\title{
NOTAS SOBRE EL PUEBLO Y LA IGLESIA DE SAN PEDRO DE CARABAYLLO
}

\author{
Arq. Luis Villacorta Santamato
}

\begin{abstract}
"En los alrededores de Lima hay pequeñas obras de arte de arquitectura colonial: las iglesias de las haciendas cercanas de nuestro valle. Unas aún reinan en el campo entre construcciones agrícolas; otras, menos distantes como la iglesia de Surco o de la Legua, están incorporadas a villorrios o a barrios de la ciudad misma"
\end{abstract}

Asi comienza un articulo que, acerca de las iglesias rurales en Lima, publicara en 1963 el arquitecto Héctor Velarde en la edición extraordinaria que con motivo de sus 25 años de fundación editó la revista El Arquitecto Peruano.

En seis páginas, don Héctor Velarde presenta e ilustra cuatro de estas obras. Desde entonces y hasta ahora muchos cambios han sucedido en la ciudad y poco o nada se ha vuelto a hablar del tema. Lima no es ya la ciudad de hace casi cuarenta años y su crecimiento desmesurado ha sido aún más rápido de lo que se ha tardado en comprenderlo, planteando problemas muy complejos, tal vez unos más que ottos, pero todos de importancia; y uno de estos problemas está justamente relacionado con nuestro patrimonio arquitectónico.

En efecto, la Ciudad de los Reyes fue fundada en territorio del antiguo señorio de Lima, y aqui floreció lo que sería una de las ciudades más bellas de América española. Sin embargo no fue ésta una ciudad aislada en el vasto territorio del valle de Lima, sino que en torno a ella se desarrolló una vida rural que en parte sostendria la vida de la urbe.

La ciudad creció, como ya sabemos, plena de magnificencia y esplendor; no obstante, los pueblos que se encontraban en el valle no dejaron de tener también ellos obras arquitectónicas dignas de apreciarse. Estas obras deben ser estudiadas desde el punto de vista de la realidad en que se dieron, distinta a la de la ciudad.

Inicialmente los pueblos indigenas -y luego en cierta medida las haciendastuvieron un planteamiento urbano $y$ arquitectónico cuya principal manifestación 
se dio precisamente en estas "pequeñas obras de arte de arquitectura colonial: las iglesias" (ibidem).

Con una expresión propia, producto de sus necesidades y condiciones particulares, estas obras expresan bastante bien la dimensión cultural del hombre del campo, especialmente del indígena.

En 1839, en su "Estadística histórica, geográfica, industrial y comercial de los pueblos que componen las provincias del departamento de Lima ", José Maria Córdova y Urrutia contaba treinta y una capillas en Lima, de las cuales quince estaban dentro de las murallas, es decir, dieciséis se encontraban en las afueras "sin incluir los oratorios de las haciendas y casas particulares".

Lima no es más la ciudad pequeña, Lima se desborda y expande encerrando en ella todo cuanto encuentra en este proceso de crecimiento. Los campos se van urbanizando y aparecen en ellos, como elementos aislados, estas edificaciones que en algunos casos la piedad popular trata de preservar aún $\sin$ los medios necesarios y, en otros, la escasez de recursos económicos, el abandono y el olvido son causa de que estas estructuras cedan al peso de sus años.

No debe considerarse monumentos solamente aquellas obras que por sus grandes dimensiones impresionan nuestro sentidos; son también monumentos todas aquellas que aủn con dimensiones menores, son muestra de auténtica belleza.

En ese sentido Lima puede aủn recuperar una serie de obras que hasta ahora se han encontrado abandonadas y, luego de un cuidadoso estudio, ampliar sus fronteras y conceptos histórico-monumentales, comprendiendo que la buena arquitectura no se dio solamente dentro de las murallas, sino también en límites mayores a los tradicionalmente establecidos.

\section{Las Iglesias Rurales en Lima}

Si realizamos un estudio de las iglesias rurales construidas en Lima durante el Virreinato, veremos que hay al menos tres tipos: las iglesias de las reducciones indigenas, las iglesias de la haciendas, y las iglesias de las devociones populares. Las más antiguas son las iglesias de las reducciones indigenas, forma de organización que adoptaron los conquistadores para la mejor catequización de los naturales y un cobro más organizado del tributo; y San Pedro de Carabayllo es precisamente una de ellas. 
Las reducciones indigenas en el Perú se llevaron a cabo de manera efectiva bajo el gobierno del Virrey Francisco de Toledo quien puso especial énfasis en la organización social del virreinato. En los primeros años de su administración recorrió parte del territorio a su cargo, dejando importantes documentos para el conocimiento de la sociedad en aquellos años. Destacan además -por lo importante de su información- las "Visitas" que mandó realizar en todo el país, lográndose un inventario detallado de la riqueza de los pueblos, empadronamiento de los indigenas, etc.

Con tal información se llevó a cabo entre los años de 1570 y 1575 , la importante empresa de congregar a los indigenas a que vivieran en comunidades o "reducciones" indigenas. En el Corregimiento del Cercado (que comprendía los valles de los rios Chillón, Rímac y Lurin) se fundaron siete reducciones incluyendo la del Callao, las que fueron:

En el Valle del Chillón: San Pedro de Carabayllo

En el Valle del Rimac: Santísima Cruz de Late

San Juan Bautista de Lurigancho

Santa Maria Magdalena

(fundada antes del Virrey Toledo)

Santiago de Surco

En el Valle de Lurin: Santísima Cruz de Pachacamac

(En el siglo XVIII Pachacamac decae

y surge San Pedro de Lurin)

Además de la del Callao.

Se fundó también la reducción de Santiago del Cercado, pero que no se podrí considerar un poblado rural sino que se consideró un poblado incorporado con la ciudad y por lo tanto una parroquia con el carácter urbano que implicaba.

En 1764, Cosme Bueno, cosmógrafo mayor del reino, decia:

"En el Corregimiento del Cercado hay además de los curatos de la ciudad y del Cercado, otros siete que son:

Lurin

Surco

Magdalena con un anexo nombrado Pachacamac

con un anexo nombrado Chortillos

con un anexo nombrado Miraflores 
Lurigancho

Hate

Carabayllo

San José de Bellavista: a un cuarto de legua del sitio en que estaba el Callao, destruido por el terremoto de 1746".

\section{Los Habitantes de Lima Prehispánica}

¿En qué se basaron los primeros españoles para la creación y ubicación de los curatos que darían a Lima una organización territorial y una demarcación que subsistiría hasta bien entrada la Independencia? ¿Y cómo se conformó especificamente el pueblo de San Pedro de Carabayllo?. Simplemente se basaron en las formas de organización territorial de los habitantes prehispánicos de la región, y de la reestructuración de uno de dichos grupos surgió el pueblo de San Pedro de Carabayllo.

Antes de la conquista por parte de los incas, la costa central del Perú (que comprende los valles de los ríos Chillón, Rímac y Lurín) se encontraba dividida en dos grandes señorios. Al norte, en el valle del río Chillón, se ubicaba el Señorio de Colli, y al sur los valles de los ríos Rímac y Lurin conformaban el Señorío de Ychma, cuya sede fue el centro religioso de Pacahacamac.

Cada uno de los dos grandes señorios estaba compuesto por otras unidades o señorios menores gobernados por "kurakas", quienes tenían autoridad sobre las guarangas, pachacas, ayllus, etc. que conformaban el curacazgo que dirigía y en el cual habia una serie de niveles sociales que resultarian dificiles de comprender actualmente. Esta compleja estratificación fue empleada por los incas para lograr un absoluto dominio de la región, siendo posteriormente desarticulada por los españoles quienes no mantuvieron sino las escalas que les podian ser útiles, sobreviviendo la autoridad del "kuraka" que pasò a llamarse "cacique" y que seria el nexo nativo entre la sociedad dominada y la sociedad dominante.

De los dos grandes señoríos existentes, el Señorío de Colli ocupaba las márgenes del rio Chillón, extendiéndose desde el mar a lo largo del valle hacia la sierra, incluyendo el curacazgo de Quivi. Estuvo conformado por varios grupos establecidos: Ios Chuquitanta, Sevillay, Guancayo, Maca, Carabayllo y Collique, formando a la llegada de los incas una población de unos diez mil tributarios. 
A causa de las constantes luchas que sostenian con sus vecinos los Canta, y luego con los incas -quienes al consolidar su dominio los fueron trasladando en grupos de mitmaq a otras regiones con el fin de evitar sublevaciones-la población fue mermando. A la llegada de los españoles no se contaba sino una guaranga (mil tributarios) en el señorio de Colli. Durante la conquista, y a causa de la explotación que sufrian, fueron disminuyendo en número. Ya en tiempos del Virrey Toledo:

"se fundó el pueblo de San Pedro de Carabayllo y consta en diversos
expedientes que se construyó en tierras que pertenecian al Cacique de
Collique"(Rostworowski 1977:43)

El Señotio de Ichma, de otra parte, se ubicó en los valles de los ríos Rímac y Lurin y alli surgirian las otras reducciones indigenas del valle.

\section{Las Reducciones Indigenas Limeñas}

Es así como se conformaron las reducciones indígenas en Lima, a base de los curacazgos prehispánicos existentes, Dichas reducciones fueton, como ya se indicó:

Al norte, en el Valle del Chillón, el pueblo de San Pedro de Carabayllo, en el cual se congregaron los habitantes del Señorio de Colli.

Al centro, en el valle del Rímac, se fundaron -además de la de Santiago del Cercado- cuatro reducciones indigenas netamente rurales. Teniendo en cuenta que

"El cabildo de Lima, el 8 de enero de 1539 habia ordenado que se diera cuatro solares fuera de la ciudad para el asiento de cada cacique delos vecinos que tenían los indios"(Málaga 1974:158)

Podemos entender que ya desde esa época se pensaba crear cuatro asentamientos en el valle del Rimac, como efectivamente se hizo. Fueron los de San Juan Bautista de Lurigancho, donde se congregaron los habitantes de la margen derecha del tio Rimac, correspondientes al antiguo curacazgo de Amancaes, Santisima Cruz de Late, en la que se agruparon los habitantes del curacazgo de Late; Santiago Apóstol de Surco, que correspondió con el antiguo curacazgo de Sulco: y Magdalena, fundada en 1557 (antes del gobierno del Virrey Toledo) en donde se congregaron los habitantes de Lima, Guatca, y Malanca (Maranga). 
Al sur, en el valle de Lurín, se creó la reducción de San Salvador de Pachacamac, que años después perdería importancia frente a Lurín, más próximo a la via de comunicación de Lima hacia el sur. Existieron en esta zona otros pequeños poblados de pescadores siendo el más destacado el de San Pedro de Quilcay, cuyos habitantes pasarian a formar parte, en el siglo XVIII, de San Pedro deLurin.

\section{San Pedro de Carabayllo}

El pueblo de Carabayllo está ubicado al N.E. de la capital, de la que dista cinco leguas. Este pueblo, que "conoce de existencia todo el tiempo de la conquista"(Córdoba y Urrutia 1839: 98) fue reconocido oficialmente como reducción indigena sólo después de 1570, ya que según la Dra. Rostworowsky: "durante el gobierno del Virrey Toledo se fundó el pueblo nuevo de San Pedro de Carabayllo, situado en la margen derecha del río Chillón”1977: 75.

En él se recogieron los habitantes del valle, correspondientes al Señorio de Colli, siendo las diversas etnias agrupadas las de los Colli, Carabayllo, Chuquitanta, Sebillay, Sutca, además de Guancayos, Micas, Missais y Guarauni, según consta en un expediente de Tributos del Corregimiento del Cercado de 1629 (BN A-443) (ibidem) y que fueron "habitantes de los pueblos destruidos nombrados Chuquitanta, Guancané, Comas y Colliqui" (Córdova y Urrutia: ibidem).

Hacia fines del siglo XVI San Pedro de Carabayllo contaba con una población de:
"sesenta indios tributarios y ocho reservados y doscientos indios de confesión y doscientas cuarenta y cinco ánimas chicas y grandes" (Diario de la Segunda Visita Pastoral que hizo de su Arquidiócesis el Ilustrisimo Señor Don Toribio de Mogrovejo, Arzobispo de Los Reyes. 1593).

Parece que hacia 1629 la población babía descendido "pues Vásquez de Espinoza en 1629 afirmaba que eran sólo 46 (párrafo 1832)"(Rostworowsky: Loc.cit.) los indigenas tributarios.

A fines del siglo XVII,

"En 1692, el pueblo contaba con ciento veinticinco ranchos y un considerable número de habitantes, pero en aquella época los 
indigenas carecian de tierras: poco a poco las habian perdido debido a la codicia de los hacendados, y sus chacras fueron a engrosar los fundos del valle, en perjuicio de los naturales (B.N. C-3422 62r)"'(op.cit: 76).

Durante todo el periodo colonial, y a pesar del acecho de las haciendas, el pueblo logró subsistir y desarrollarse gracias a que

"En ese entonces el Camino Real de Trujillo a Lima , llamado también Camino Real de los Llanos, pasaba por él, y este hecho daba movimiento a la población" (op.cit.:75)

Con la creación del ferrocarril Lima-Ancón, en la segunda mitad del siglo XIX, que seguia la ruta de la actual carretera Panamericana al norte, el pueblo quedó aislado de la via por lo que la población dio en trasladarse a un punto más próximo al paso del ferrocarril, despoblándose Carabayllo progresivamente y surgiendo el poblado de Puente Piedra.

Con la aparición de la carretera, la antigua reducción quedó apartada de Lima, y recién se ha vuelto a tener fácil acceso gracias a la pista que se concluyó hace unos lustros y que justamente pasa por detrás de la iglesia del pueblo, encontrándose en el camino a Guarangal, donde se ubicó la Central Atómica del Perú, y con motivo de lo cual se construyó la vía mencionada.

Carabayllo tenia un anexo, que en en las "Guias" de Cosme Bueno de 1764 aparece como Lancón y que correspondería a Ancón, caleta de pescadores al N.O. de Lima, de donde dista seis leguas camino a Chancay, en un paraje en el cual forman los cerros una ensenada en forma de herradura, resguardando la playa de vientos del sur. En 1839, decía Córdova y Urrutia que "sus habitantes que son en número sesenta y tres indigenas, treinta y tres hombres y treinta mujeres están dedicados a la pesca"(Córdova y Urrutia, 1839:100)

En Ancón existió una pequeria capilla bajo la advocación de San Pedro Pescador, pero quedó destruida en 1940, por lo que se ha levantado la nueva iglesia de San Pedro Pescador, de estilo neocolonial, para los pobladores del distrito.

\section{El Curato de Carabayllo}

El Curato de Carabayllo fue fundado por los religiosos de La Merced, quienes establecieron una doctrina desde los primeros tiempos de la conquista, 
aún antes de la fundación de Lima. Para su sustento gozaba la doctrina de un sinodo de ciento ochenta y siete pesos según consta en un documento de la época:

"En el pueblo de Caraguaillo estän reunidos el repartimiento de Chuquitanta y Sibillay de la encomienda de don Gerónimo de Guevara y el de Comas y Caraguaillo de Hernán Carrillo y el de Guancayo de Gonzalo Cáceres, doctrinales un frayle de la Orden de la Merced. Por las retesas tiene de signodo cada año 187 pesos" (Relación sobre las doctrinas que tienen los frayles de todas las Ordenes en el Arzobispado de los Reyes y el estipendio que se les da, hecha por orden superior y suscrito por el escribano real D. Fco. de Ascanio 15986 de abril). En (Lisson Chaves 1943: 216)

Existia en la iglesia una cofradía de Nuestra Señora del Rosario que tenía concedidos tres jubileos, sin renta alguna. Aunque posteriormente el sínodo se elevó a 190 pesos, la doctrina no contaba con muchos recursos económicos propios y no hemos hallado documentos que indiquen lo contrario.

La doctrina fue la primera que

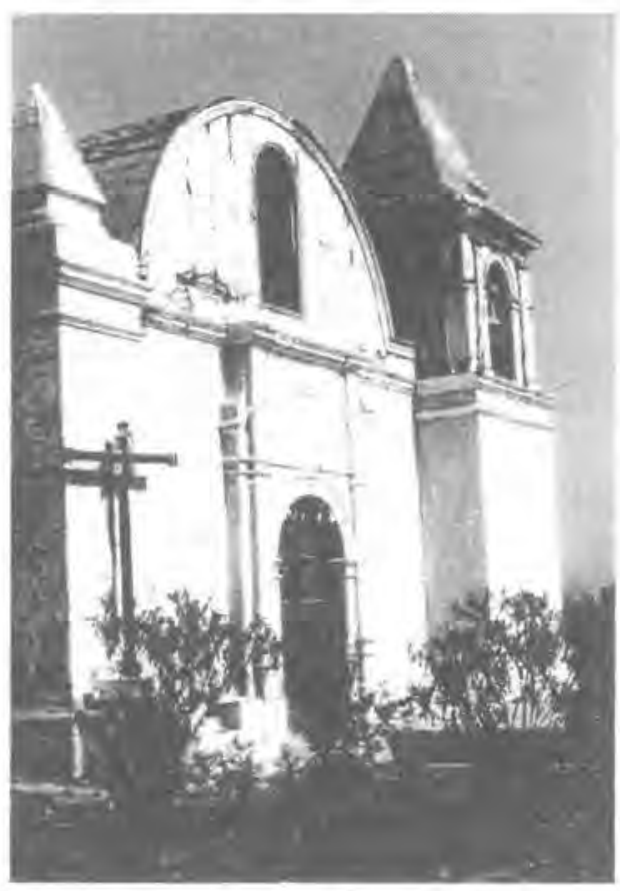

IGLESIA DE SAN PEDRO DE CARABAYLLO visitó en su segunda visita pastoral a la Arquidiócesis de Lima el santo arzobispo don Toribio de Mogrovejo . Este hecho puede haber dado origen a la tradición según la cual fue esta iglesia el "lugar donde ofició su primera misa Santo Toribio de Mogrovejo, hace más de cuatrocientos años" (Cubillas 1974: 102) y que aún cuentan con orgullo los pobladores de Carabayllo. De esta visita, en la cual confirmó a cuarenta y tres personas, queda un documento, el "Diario de la Segunda Visita Pastoral que hizo de su Arquidiócesis el Ilustrísimo Señor Don Toribio Alfonso de Mogrovejo Arzobispo e Los Reyes", y que ha sido publicado en la Revista del Archivo Nacional del Perú.

En 1768 se prohibió que los religiosos tuvieran doctrina a su cargo y San Pedro de Carabayllo pasó al cuidado 
de clérigos. En la primera mitad del siglo XIX continuaba siendo la única parroquia en el Valle del Chillón. Un documento de la época dice:

"... en la actualidad (el curato) es servido por un clérigo y sus preventos están calculados en mil pesos anuales.

Demostración

\begin{tabular}{llllllll} 
& \multicolumn{3}{c}{ Población } & \multicolumn{2}{c}{ Utilidad } & \multicolumn{2}{c}{ Contribuciones } \\
& Hbs. & Mgs. & Total & que reportan & Nacion. & Ecles. \\
Castas & 334 & 230 & 564 & 65933 & 3172 & 1979 & 5400 \\
Indígenas & 151 & 123 & 274 & 5200 & 260 & 1800 \\
Total & 485 & 353 & 838 & 71133 & 3172 & 2238 & 7200 \\
En castas están incluidos & 519 esclavos"(Córdova y Urrutia 1839:100)
\end{tabular}

\section{Iglesia de San Pedro de Carabayllo}

Llegando por la nueva carretera de camino a Guaranjal (desvío de la carretera Panamericana a la altura de Puente Piedra), la primera impresión que se tiene de Carabayllo es por su iglesia, la que muestra sus voluminosos muros y contrafuertes en medio de un paisaje de sembrios y árboles.

En la actualidad Carabayllo es un pequeño poblado con unas cuantas calles de suelo afirmado, formado por viviendas de adobe y quincha de un solo piso y cuyo principal espacio urbano es, desde tiempos coloniales, la plaza. En torno a ella se encuentran aún los edificios principales de todo pueblo indigena: a un lado la casa cural, pequeña edificación de una planta con tres habitaciones y huerto posterior; perpendicular a ésta, el templo, precedido por un atrio; el cementerio y a un lado el depósito de andas.

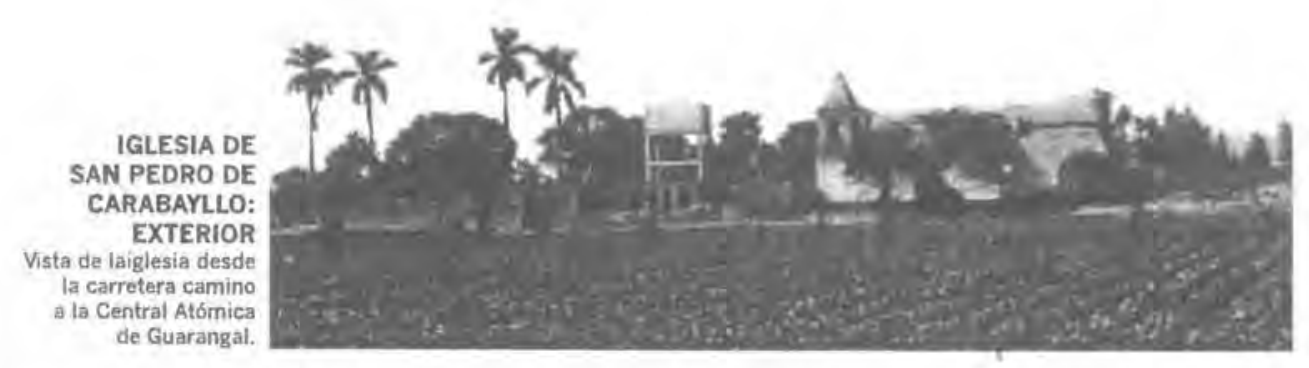


El edificio de la iglesia es una edificación singular. Ubicado perpendicularmente a la plaza, es de planta rectangular, de $8.20 \mathrm{mts}$. de ancho por $24.75 \mathrm{mts}$. de largo, cumpliendo de manera muy aproximada la relación de tres veces el largo de la nave que el ancho, proporción que no encontraremos en otras iglesias de doctrina sino en las rurales de jesuitas, de fundación muy posterior. De una sola nave, está cubierto el espacio por una gran bóveda de cañón que va desde el muro frontal hasta el posterior, unificándolo totalmente.

Hacia el lado de la epístola se encuentra, próximo al ingreso, el baptisterio, pequeña habitación donde no queda hoy sino una pila de mármol aparentemente de fábrica reciente- y la escalera de acceso al coro y al campanario. El coro, sobreelevado del nivel de la nave, está iluminado por una ventana de más de dos metros de alto que remata en arco de medio punto y compensa dada su área- la poca iluminación y ventilación que pueden ofrecer las cuatro ventanas altas (bastante pequeñas) a los lados de la bóveda. El coro está resguardado por una balaustrada de madera muy simple. El campanario, al que se accede por la misma escalera, es de planta cuadrangular, todo de madera y techumbre de quincha, estando apoyado sobre la torre, sólida estructura de ladrillo.

Hacia el lado del evangelio, y a mitad de la nave, se ubica la portada lateral que servia de acceso al cementerio y hoy se encuentra clausurada.

Tras el presbiterio, a eje de la nave, se encuentra la sacristía, pequeña habitación de techo plano de vigas de madera o alfajías a la que se tiene acceso por dos puertas ubicadas simétricamente a dicho eje y que debieron ser probablemente motivo de trabajo en el retablo del altar mayor.

El retablo del altar mayor, como los demás laterales ya no existen pues la iglesia según informaciones orales- fue presa de un voraz incendio a inicios del siglo $\mathrm{XX}$, reemplazándose el antiguo retablo por el pequeño tabernáculo neogótico que hoy se encuentra, salvándose únicamente unas cuantas tallas de imágenes que se conservan, algunas de las cuales se han puesto entre molduras de arcos a modo de retablos laterales, entre ellos la imagen de San Pedro, patrón del pueblo, y una imagen de Nuestra Señora del Rosario cuya cofradia data del siglo XVIII. Sólo en el sotacoro, junto a la puerta del baptisterio, queda un pequeño retablito dedicado a San Isidro Labrador, quien aparece con un arado de bueyes en una especie de templete neoclásica el cual data probablemente de la época republicana. 


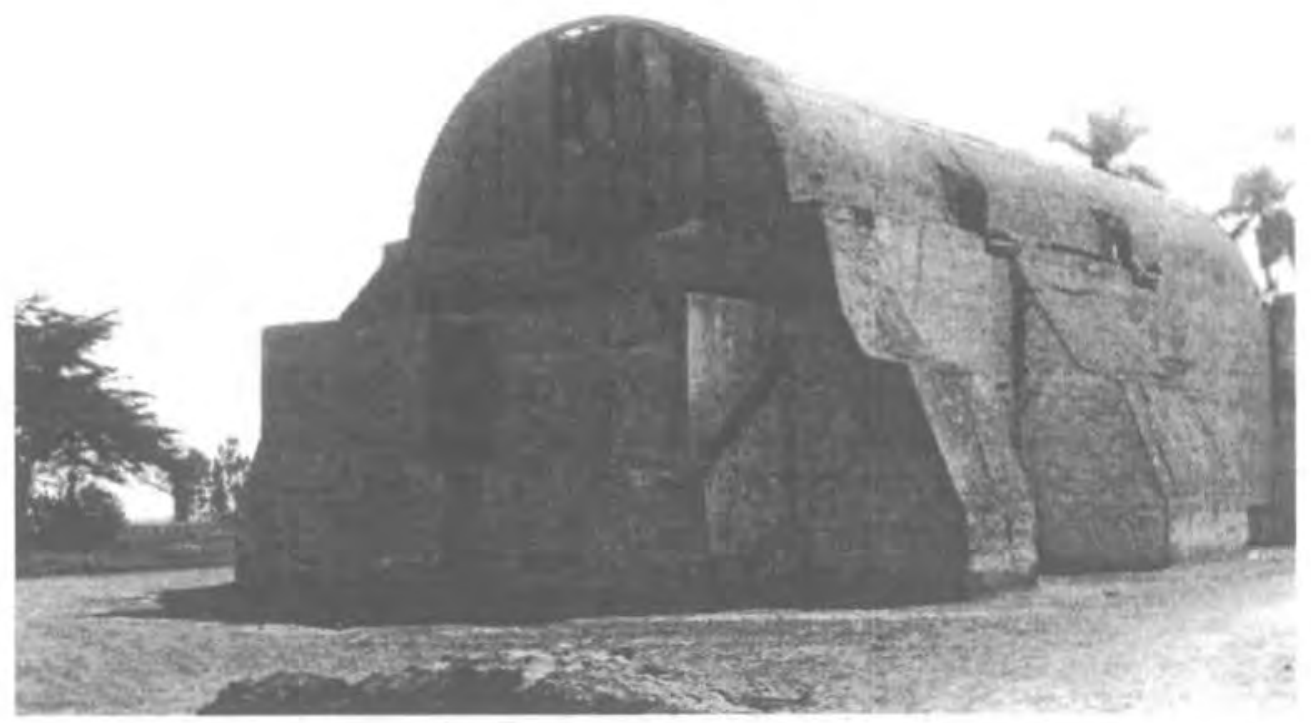

IGLESIA DE SAN PEDRO DE CARABAYLLO: VOLUMETRIA

Exteriormente las dimensiones de los muros y contrafuertes

dan una volumetría de gran solidez destacando la

clara concepción estructural de su función.

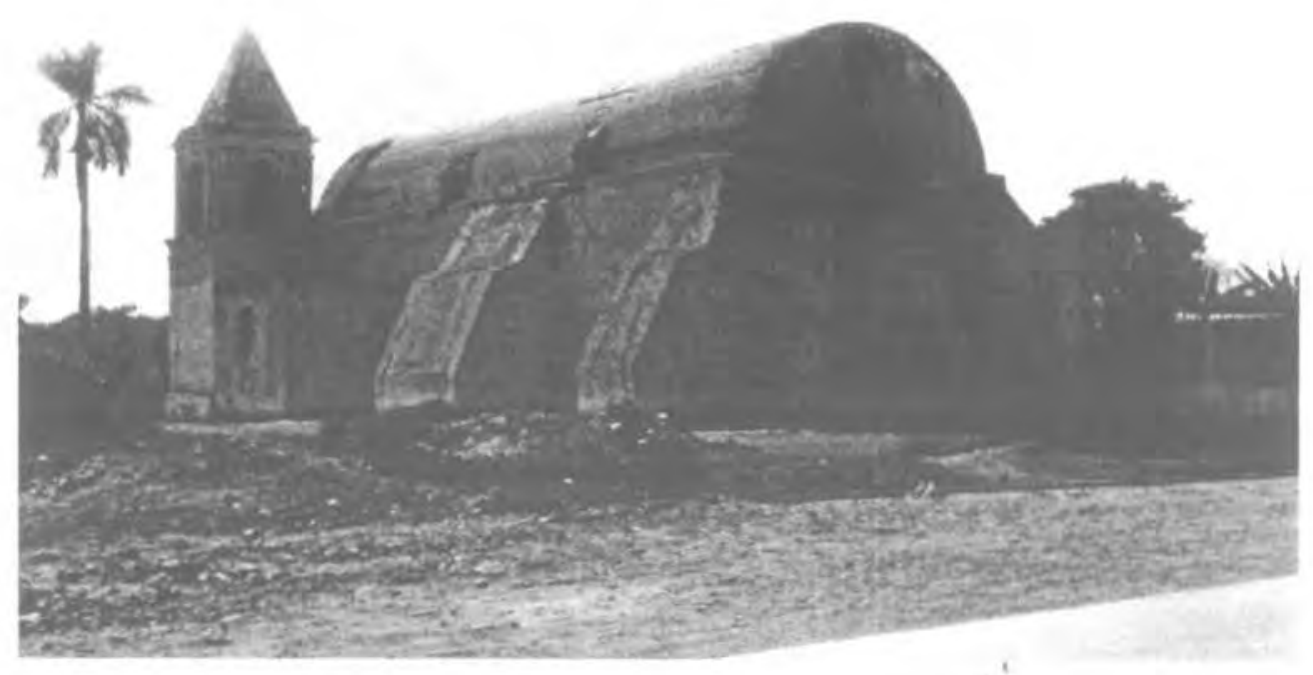


En el retablo del altar mayor se tenia acceso a la hornacina principal desde Ia sacristía, la cual debió servir también como especie de camarín para la imagen principal. Algunas de las imágenes de este retablo se han conservado hasta nuestros días y nos permiten apreciar que guardan semejanza con los que encontramos en otras iglesias parroquiales de Lima con cuyos retablos debió tener cierta semejanza. Este retablo mayor incendiado probablemente haya sido edificado hacia fines del siglo XVIII. Entre las imágenes que de él han sido conservadas se encuentra una del Padre Eterno, busto con los brazos extendidos a manera de bendecir y que debió ser coronación del retablo pues imágenes similares coronan los altares de dos iglesias limeñas, una de las cuales es la de Los Huérfanos (retablo obra del entallador José Manuel Palomares). Igualmente dos imágenes que aún hoy se conservan en el presbiterio de Carabayllo, posiblemente San Joaquín y Santa Ana, son también semejantes a las que de los mismos santos se encuentran en el retablo mayor de la Iglesia de Los Huérfanos.

La estructura de la iglesia es como todas, de ladrillo, caña y adobe, destacando en su volumen la solidez de sus contrafuertes.

La fachada de la iglesia es de concepción simétrica con respecto al eje central, aunque esta simetría no se produce rigidamente por cuanto cuenta con una sola torre con campanario al lado del evangelio- equilibrando la composición una estrecha torrecilla que remata en una especie de pinón y delante de la cual se presenta la cruz del camino. Esta equilibrada asimetría no es vista en ninguna otra iglesia rural.

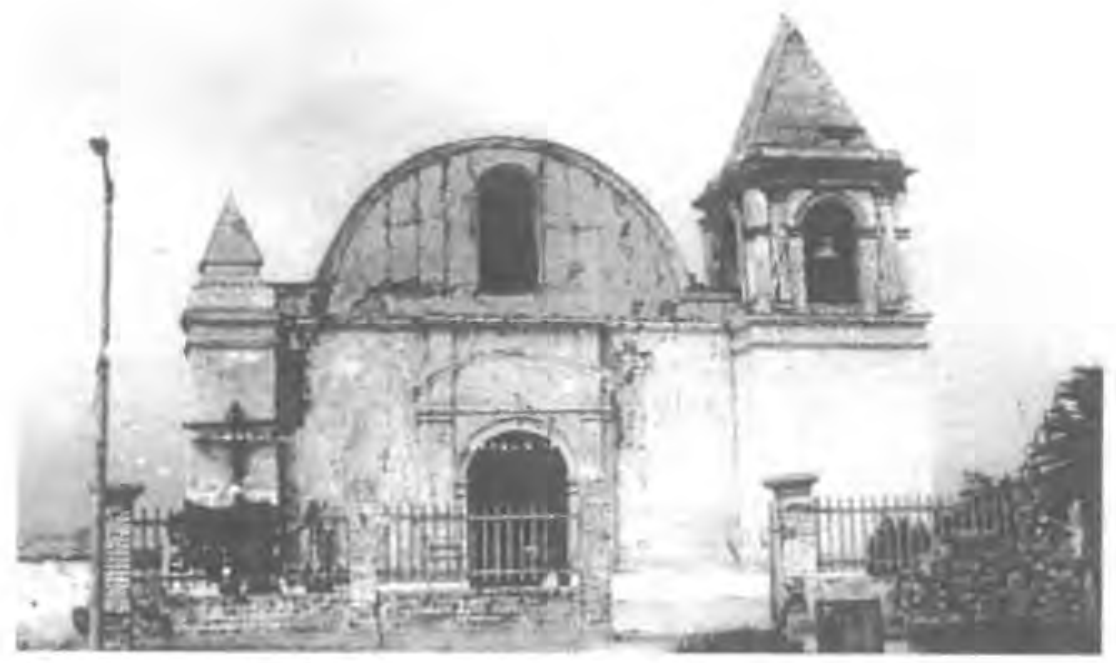




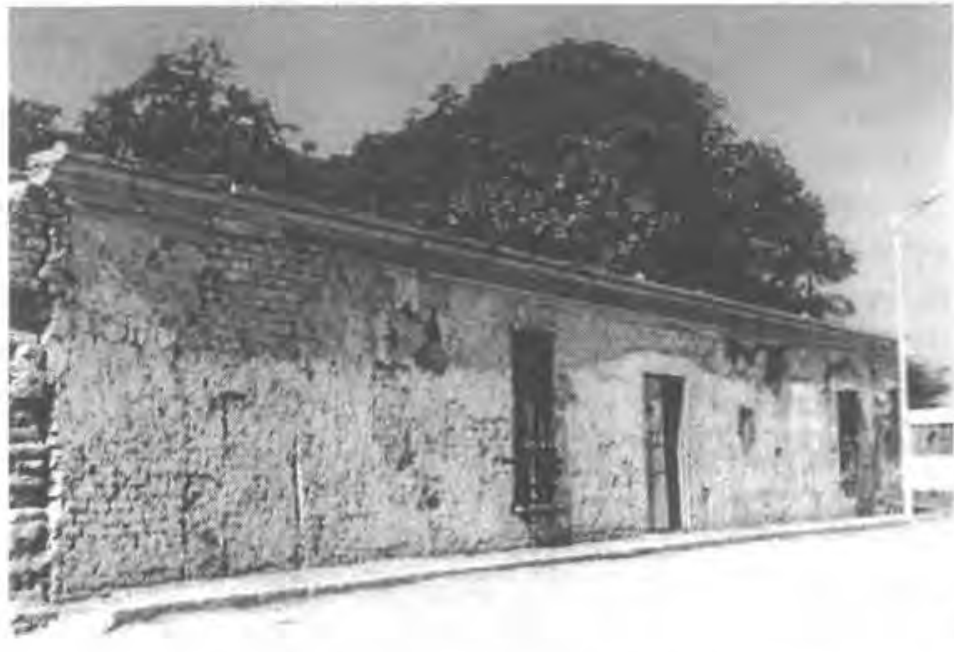

Este frente, de una sencillez y armonía extraordinaria, responde a criterios de composición muy clásicos, logrando con pocos elementos una extraordinaria obra de proporción y unidad. Las torres no siguen el alineamiento de los muros laterales sino que éstas se separan desplazándose del eje de los mutos dándole al frente una mayor amplitud. Esta separación permite crear en el espacio comprendido entre las torres un paño rectangular de sección áurea, es decir, la distancia entre las torres es aproximadamente un poco más de 1.6 veces la distancia del suelo a la cornisa o arranque de la bóveda. Todo rectángulo de sección aúrea está formado a su vez por un cuadrado y otro rectángulo de sección de oro. En este caso, la portada se ubica respetando ciertas reglas de composición: las jambas de la puerta se encuentran en los extremos de los dos cuadrados que se pueden ubicar dentro del rectángulo aúreo, y los extremos de las pilastras que enmarcan el arco desde el suelo a la cornisa se ubican en la intersección de las diagonales de dichos cuadrados.

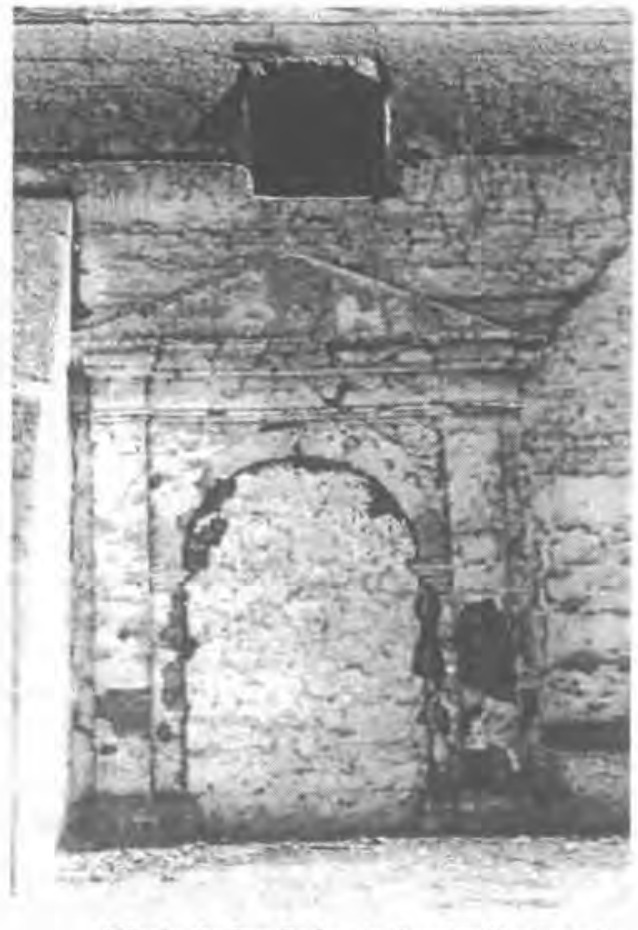

Iglesia de San Pedro de Carabayllo: Exterior 
Así, se puede ver que la posición de la puerta responde a criterios basados en la sección áurea, dado que las jambas se ubican en los extremos de los cuadrados que se inscriben en el rectángulo áureo, con lo que la distancia de una torre a la jamba más próxima guarda con la distancia total entre torres una proporción áurea, cumpliendo el enunciado correspondiente: "la parte menor es a la mayor como la mayor es al todo".

En el sentido vertical se encuentra también la proporción áurea: la altura total desde el suelo hasta la cornisa guarda con el vano de entrada la misma proporción que el vano guarda con la distancia que lo separa de la
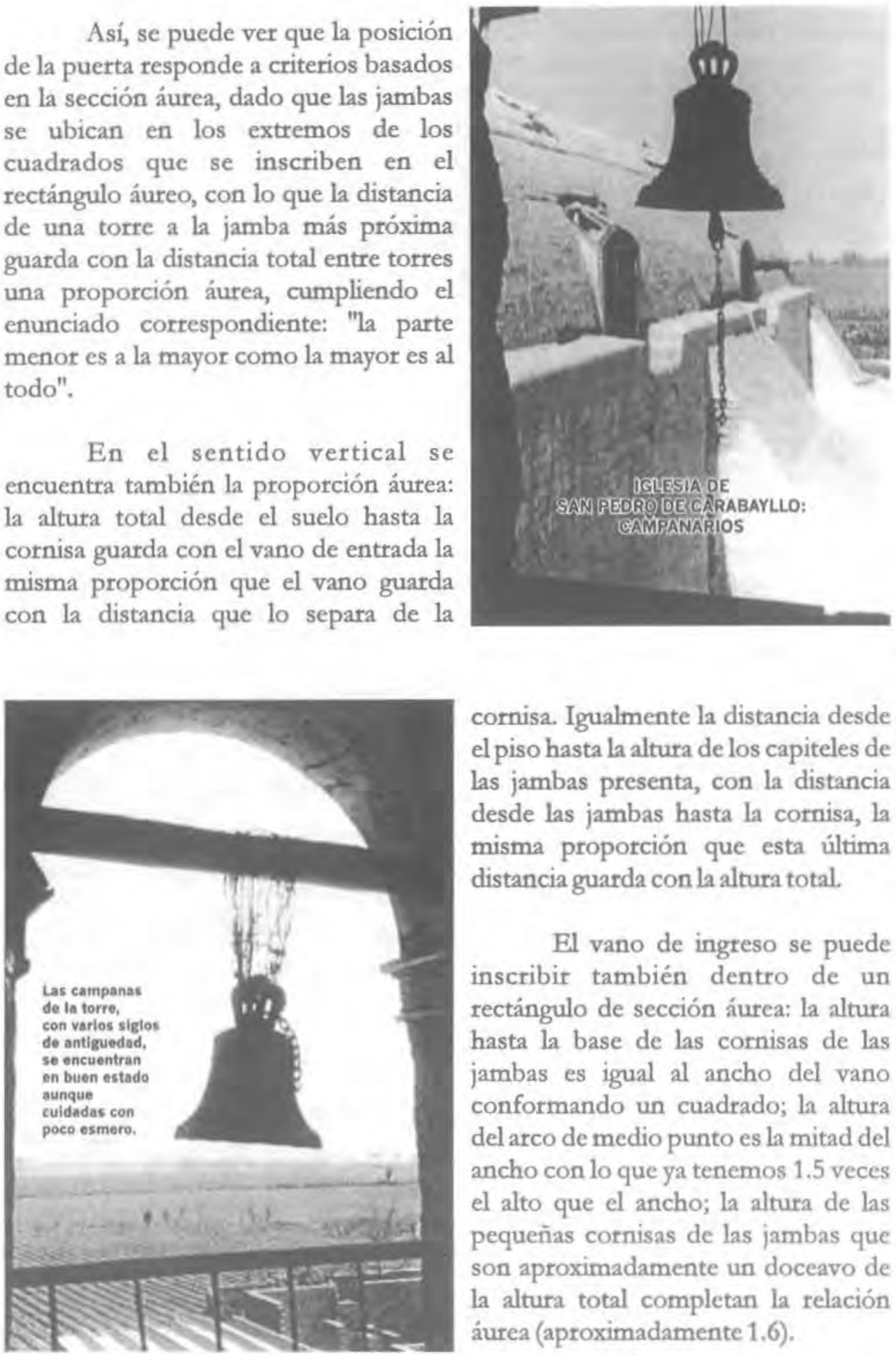

cornisa. Igualmente la distancia desde el piso hasta la altura de los capiteles de las jambas presenta, con la distancia desde las jambas hasta la cornisa, la misma proporción que esta última distancia guarda con la altura total.

El vano de ingreso se puede inscribir también dentro de un rectángulo de sección áurea: la altura hasta la base de las cornisas de las jambas es igual al ancho del vano conformando un cuadrado; la altura del arco de medio punto es la mitad del ancho con lo que ya tenemos 1.5 veces el alto que el ancho; la altura de las pequeñas cornisas de las jambas que son aproximadamente un doceavo de la altura total completan la relación áurea (aproximadamente 1,6). 


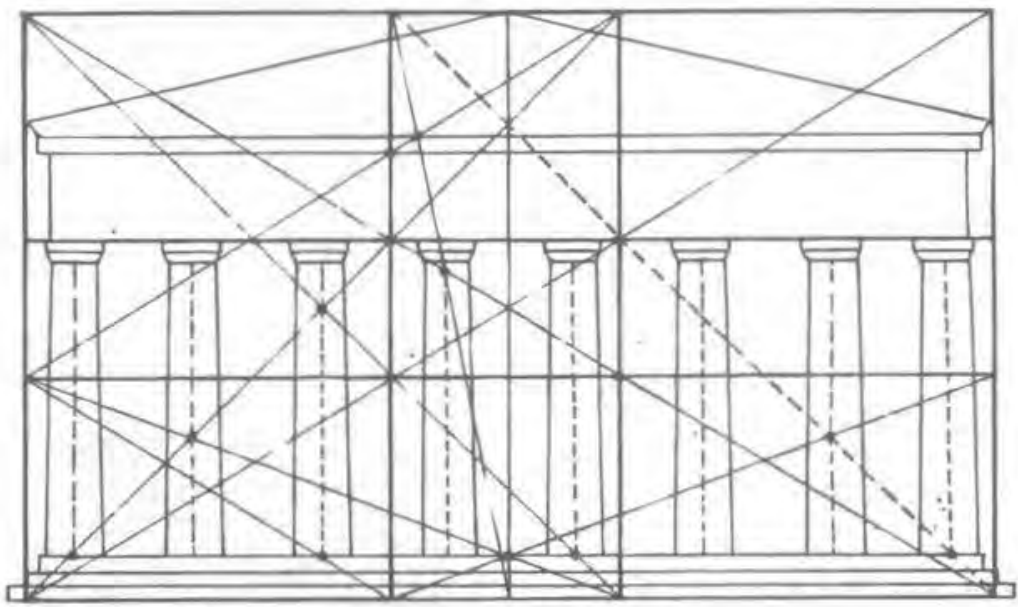

Fuente: Villacorta Paredes, Juan: 1966: 37

Muchos de loa criterio de componición utilizados durante la colonia son criterios de valider universal. El Análisis geométrico del frete de la iglesia de San Pedro de Carabay110 (h. SXVIII, DC. abajo), presenta un esquema muy similar al empleado en el Partenón (S,V AC. arriba).

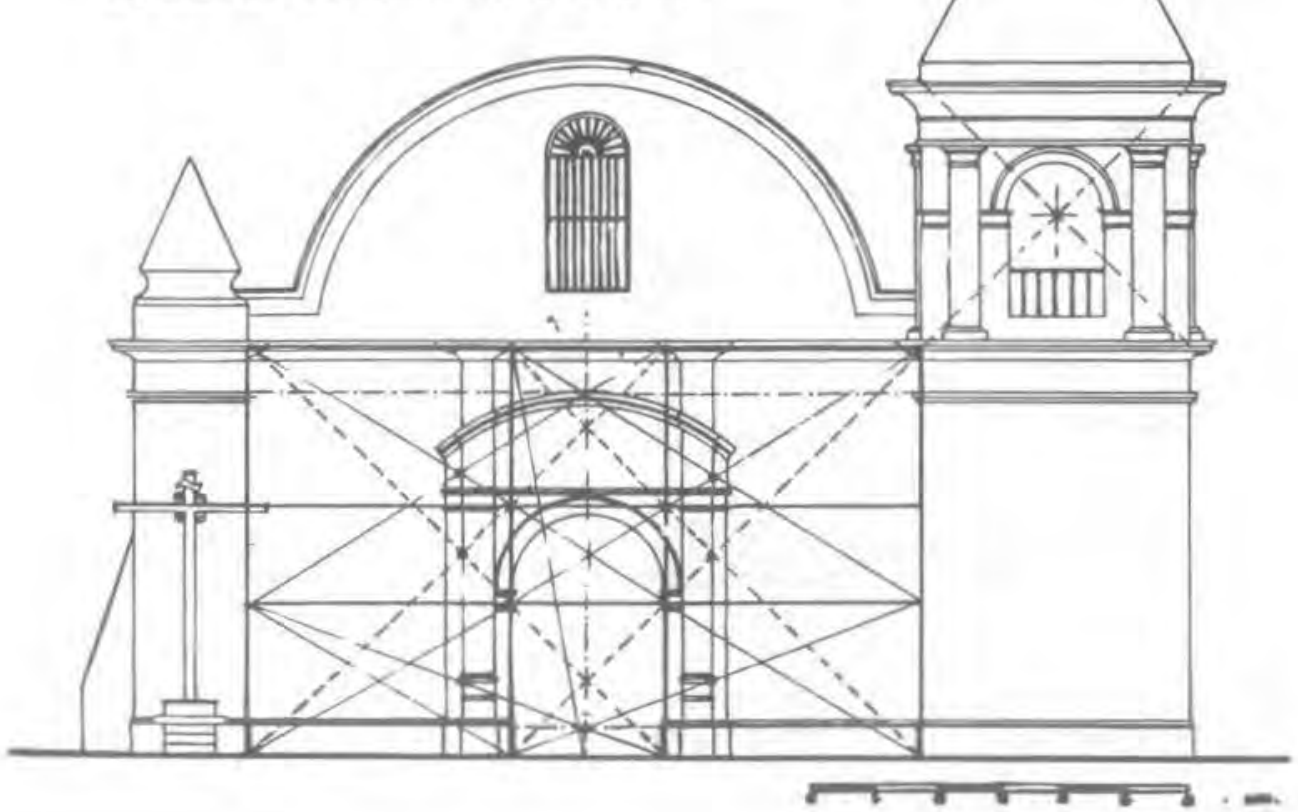


La sobria portada está enmarcada por gruesas pilastras cuyos extremos coinciden con el cruce de las diagonales de los cuadrados correspondientes. Estas pilastras están a su vez entre pequeñas pilastrillas con las que se encuentra también en relación armónica. De manera muy aproximada porque el enlucido no es siempre parejo y es producto de sucesivas reparaciones- la pilastra central mide $50 \mathrm{~cm}$., las laterales hacia las torres $-20 \mathrm{~cm}$. y las jambas $30 \mathrm{~cm}$. de ancho cada una, de modo que las tres se relacionan armónicamente.

La moldura a modo de frontón curvo que se desarrolla sobre el arco de ingreso guarda también ciertas proporciones: la altura del frontón medida desde la cornisa inferiot, es en su eje de simetria el doble de las
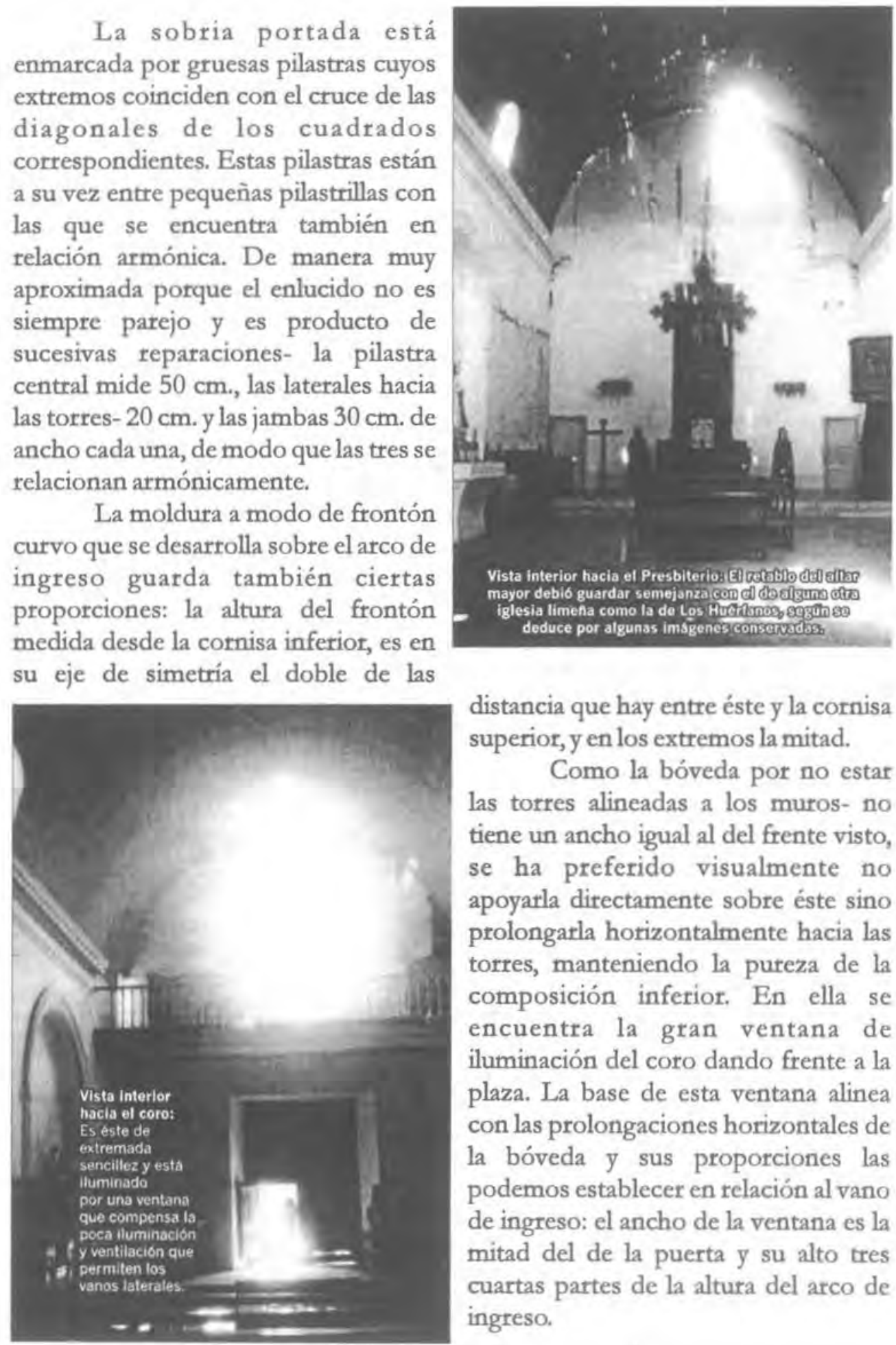

distancia que hay entre éste y la cornisa superior, y en los extremos la mitad.

Como la bóveda por no estar las torres alineadas a los muros- no tiene un ancho igual al del frente visto, se ha preferido visualmente no apoyarla directamente sobre éste sino prolongarla horizontalmente hacia las torres, manteniendo la pureza de la composición inferior. En ella se encuentra la gran ventana de iluminación del coro dando frente a la plaza. La base de esta ventana alinea con las prolongaciones horizontales de la bóveda y sus proporciones las podemos establecer en relación al vano de ingreso: el ancho de la ventana es la mitad del de la puerta y su alto tres cuartas partes de la altura del arco de ingreso. 
La torre del campanario es también de sección aúrea: la relación entre la altura del suelo a la cornisa y su ancho guardan dicha proporción.

El campanario es más bien un cubo donde cada uno de sus lados en un cuadrado cuyo cruce de diagonales coincide con el punto central del arco de medio punto. En cada uno de los cuatro lados del campanario hay adosadas pilastras dóricas de madera que enmarcan los arcos de las campanas.

No se ha podido determinar si originalmente la iglesia tuvo dos campanarios y lo más probable es que no los haya tenido-, sin embargo la pequeña torrecilla lateral coronada por el piñón enmarca y equilibra muy bien la estudiada composición del frente de fachada.

Sobre el muro lateral de la iglesia, al exterior, está la portada que servía de comunicación entre el cementerio y la iglesia, y que a pesar de estar hoy clausurada, no deja de ser motivo de admiración por la sencillez sus lineas y la exactitud de sus proporciones.

La estructura del templo es de adobe y ladrillo, y la bóveda de caña de acuerdo a la estructuración que generalmente tienen este tipo de iglesias.

Lo que más llama la atención por estar totalmente expuesto es la voluminosidad de los contrafuertes que dan una sensación de solidez al conjunto. El volumen de la sacristía en la parte posterior, por ser de menor altura que la iglesia, contribuye a acentuar esta sensación de transmisión de fuerzas de la bóveda al suelo, apareciendo como un elemento más en dicha transición.

El depósito de andas es una habitación independiente, de techo plano de cañas y torta de barro ubicado próximo a la iglesia, siempre en torno a la plaza.

Arq. Luis Villacorta Santamato Universidad Nacional de Ingenieria 

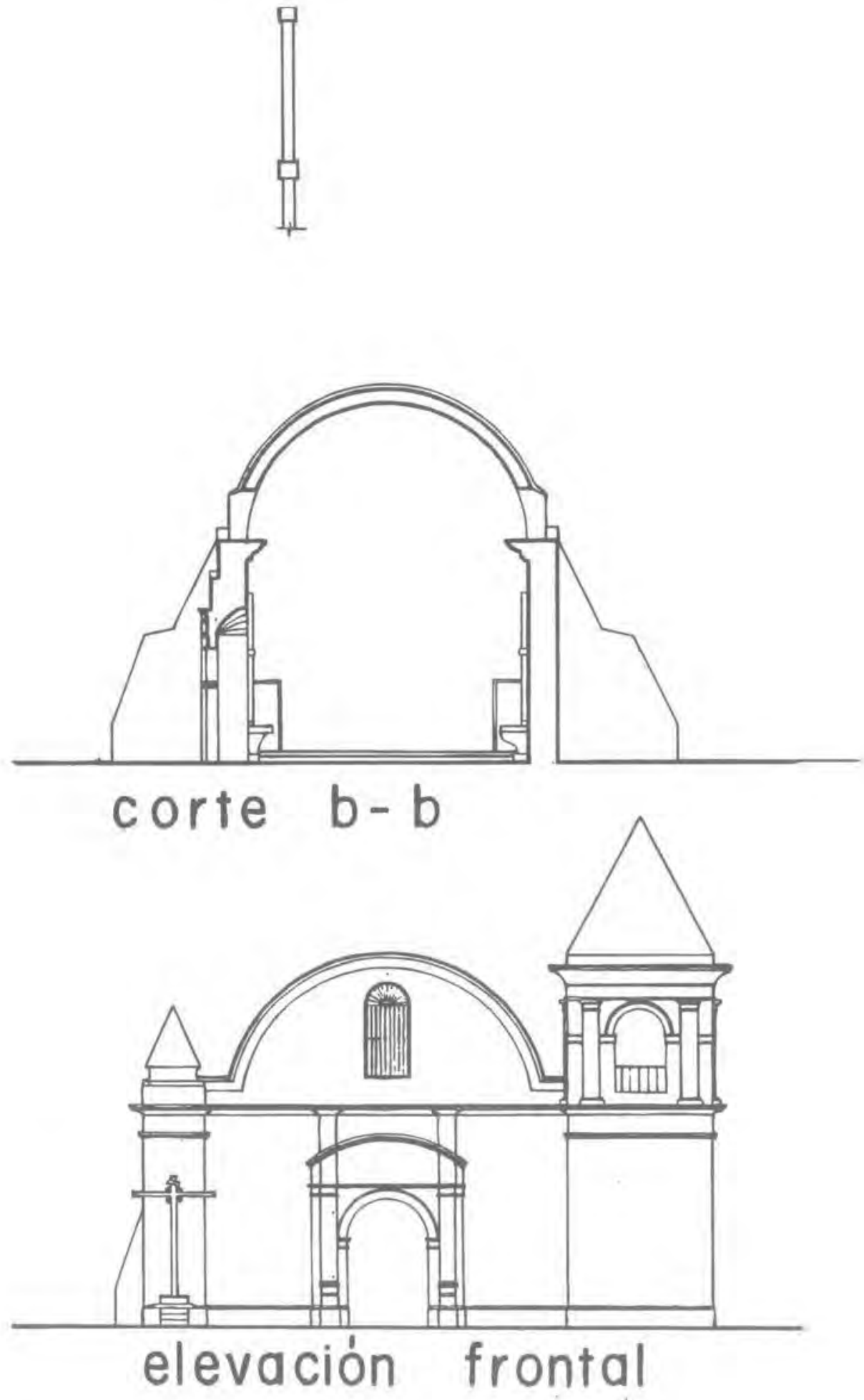

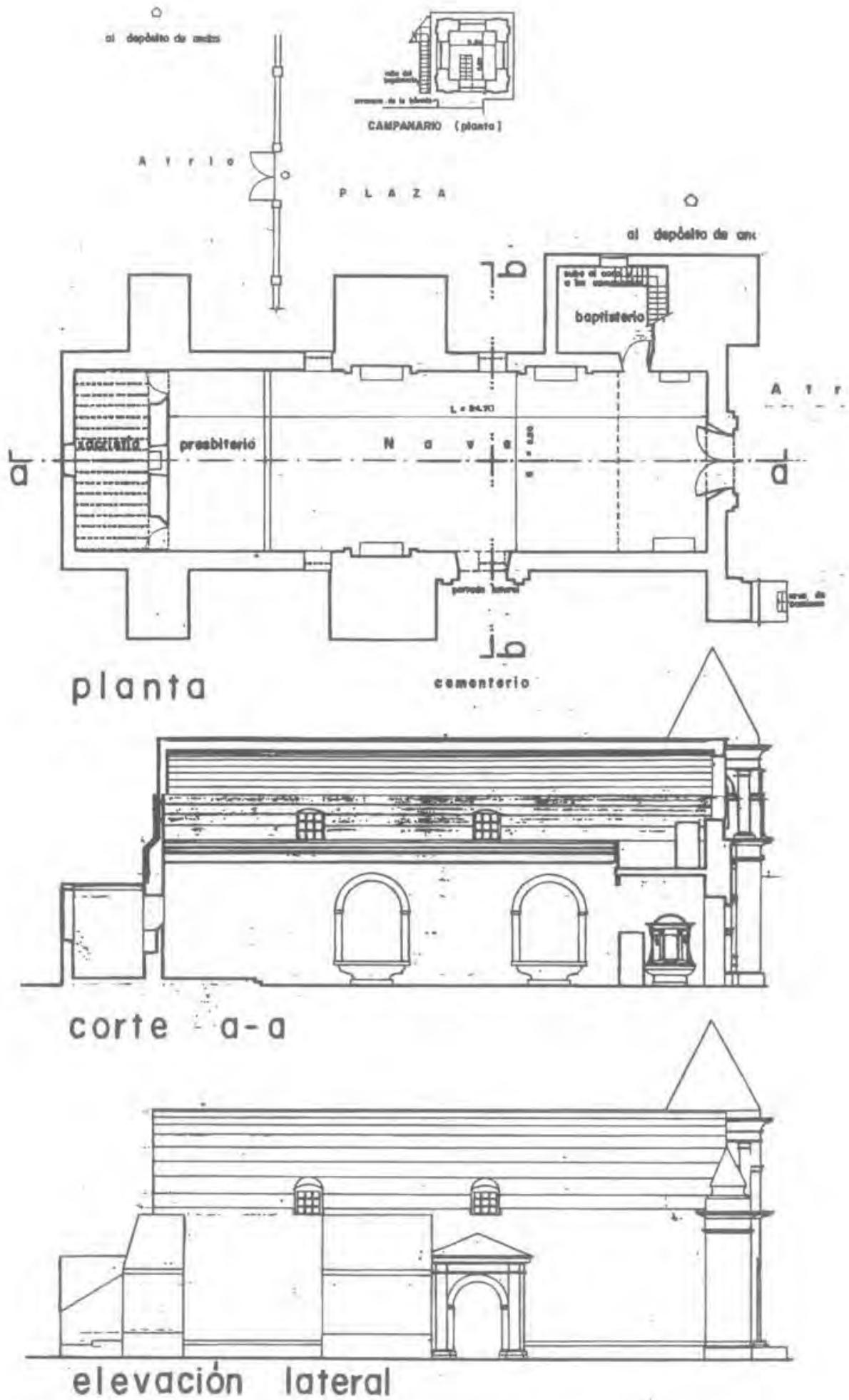


\title{
BIBLIOGRAFÍA
}

\section{Acosta, Antonio}

1982 Religiosos, doctrinas y excedente económico indigena en el Perú a comienzos del siglo XVII en Histórica vol. VI num: 1 julio de 1982: 1-32. Lima, Departamento de Humanidades. Pontificia Universidad Católica del Perú.

\author{
Acosta, José de \\ 1954 (1588) De procuranda inderum salute, en Obras, Madrid BAE. \\ (1590) Historia Natural y Moral de las Indias, en Obras. Madrid \\ BAE
}

Alcedo, Antonio de

1786

Diccionario Geográfico, Histórico de las Indias Occidentales o América.

\section{Anónimo}

1920

Diario de la Segunda Visita Pastoral que hizo de su Arquidiócesis el Tlustrísimo Señor Don Toribio Alfonso de Mogrovejo Arzobispo de Los Reyes", en Revista del Archivo Nacional ti: 49 ss. tII: 37 ss. , Lima.

1928 Donación hecha por el Cacique del valle de La Magdalena, D. Gonzalo, a los frailes de S. Francisco del sitio de su iglesia y Monasterio. 1557" en Revista del Archivo Nacional tVI: 13-14

\section{Bartra, E} 1982

Tercer Concilio Limense 1582-1583, Versión original de los decretos con el Sumario del Segundo Concilio Limense, edición conmemorativa del IV centenario de su celebración. por el $\mathrm{P}$. Enrique Bartra S.J., Lima.

Bueno, Cosme

1764

Descripción de las provincias pertenecientes al Arzobispado de Lima, Lima 1764 
Cordova y Urrutia, José María

1839 Estadistica bistórica, geográfica, industrial y comercial de lospueblos que componen las provincias del departamento de Lima, Lima.

Cubillas, Margarita

1974 LimaMonumental, Edit. Lumen S.A.Lima

Fuentes, Manuel Atanasio.

1858 Estadística General de Lima, Lima.

Lisson Chaves, Emilio

1943-1956 LaIglesia de España en el Perú. Colección de documentos para la historia de la Iglesia en el Perú, que se encuentran en el Archivo General de Indias, Sevilla, 5 vols.

\section{Málaga Medina, Alejandro}

1974 Las Reducciones en el Perú (1532 1600) en Historiay Cultura No 8141-142

1979 Aspecto Urbano de las Reducciones Toledanas en Historiay Cultura

No 88:167-183,Lima.

\section{Marzal. Manuel}

1983

La transformación Religiosa Peruana, Pontificia Universidad Católica del Perú, Lima.

Matos Mar, José

1978

Prólogo a Señorios Indígenas de Lima y Canta, Rostworowsky 1978, I.E.P.Lima.

Rostworowsky De Diez Canseco, María

1977 Etriay Sociedad,Lima, I.E.P.

1978 Señorios Indigenas de Limay Canta, Lima, I.E.P. 


\section{Vargas Ugarte, Rubén}

1951

Los Concilios Limenses (1551-552) Lima, t: 1.

1952

Los Concilios Limenses (1551-772) Lima, $t: 2$.

1953

Historia de la Iglesia en el Perź, Burgos, t: 1.

1954

Los Concilios Limenses (1551-772) Lima, t: 3

1959

Historia de la Iglesia en el Perú, Burgos, t: 2.

1960

Historia de la Iglesia en el Perú, Burgos, t: 3.

1961

Historia de la Iglesia en el Perú, Burgos, t: 4.

1962

Historia de la Iglesia en el Penú, Burgos, t: 5 .

1968

Ensayo de un diccionario de artifices de la América Meridional, Burgos

\section{Villacorta Paredes, Juan}

1966

Artes Plásticas: Composición Artistica y Retrato, Escuela Salesiana de Artes Gráficas. Lima. 